\title{
The Role of Osteopontin in Tumor Progression and Metastasis in Breast Cancer
}

\author{
Lígia R. Rodrigues, ${ }^{1}$ José A. Teixeira, ${ }^{1}$ Fernando L. Schmitt, ${ }^{2,3}$ Marie Paulsson, ${ }^{4}$ \\ and Helena Lindmark-Mänsson ${ }^{4,5}$ \\ Institute for Biotechnology and Bioengineering, Centre of Biolngical Engineering, Campus de Gualtar, Braga, Portugal. \\ ${ }^{2}$ Instituto de Patologia e Imunologia Molecular, ${ }^{3}$ Faculdade de Medicina, Universidade do Porto, Oporto, Portugal; \\ 'Department of Food Technology, Engineering, and Nutrition, Lund University; and \\ ${ }^{5}$ Swedish Dairy Association, Lund, Sweden
}

\begin{abstract}
The use of cancer biomarkers to anticipate the outlines of disease has been an emerging issue, especially as cancer treatment has made such positive steps in the last few years. Progress in the development of consistent malignancy markers is imminent because advances in genomics and bioinformatics have allowed the examination of immense amounts of data. Osteopontin is a phosphorylated glycoprotein secreted by activated macrophages, leukocytes, and activated $T$ lymphocytes, and is present in extracellular fluids, at sites of inflammation, and in the extracellular matrix of mineralized tissues. Several physiologic roles have been attributed to osteopontin, i.e., in inflammation and immune function, in mineralized tissues, in vascular tissue, and in kidney. Osteopontin interacts with a variety of cell surface receptors, including several integrins and CD44. Binding of osteopontin to these cell surface receptors stimulates cell

adhesion, migration, and specific signaling functions. Overexpression of osteopontin has been found in a variety of cancers, including breast cancer, lung cancer, colorectal cancer, stomach cancer, ovarian cancer, and melanoma. Moreover, osteopontin is present in elevated levels in the blood and plasma of some patients with metastatic cancers. Therefore, suppression of the action of osteopontin may confer significant therapeutic activity, and several strategies for bringing about this suppression have been identified. This review looks at the recent advances in understanding the possible mechanisms by which osteopontin may contribute functionally to malignancy, particularly in breast cancer. Furthermore, the measurement of osteopontin in the blood or tumors of patients with cancer, as a way of providing valuable prognostic information, will be discussed based on emerging clinical data. (Cancer Epidemiol Biomarkers Prev 2007;16(6):1-11)
\end{abstract}

\section{Introduction}

Recently, the use of cancer biomarkers to predict future patterns of disease has been an emerging issue, especially as cancer treatment has made such positive strides in the last few years (1-11). Breakthroughs in the development of reliable cancer biomarkers may be imminent because of advances in genomics and computer technology, which allow the analysis of vast quantities of data (12-17).

A biomarker is any substance, which when detected in biological samples or tissues, is associated with an increased risk of a disease. The term cancer biomarker most commonly refers to serum markers such as the prostate-specific antigen; markers for inherited mutations, such as the breast and ovarian cancer susceptibility genes $B R C A 1$ and $B R C A 2$, and markers for somatic or noninherited mutations, which account for most cancers (18-20). Growth factors, which circulate in the blood and may contribute to the development of tumors, are under investigation as possible cancer biomarkers.

Despite promising new methods and findings, controversy abounds in this field, as a consequence, none of the biomarkers used nowadays have adequate sensitivity, specificity, and predictive value for population screening (21). Nevertheless, it is highly desirable to pursue new biomarkers suitable for population screening and early diagnosis (22).

Received 12/1/06; revised 2/12/07; accepted 3/13/07.

Grant support: The Fundação para a Ciência e a Tecnologia, Portugal provided financial support through postdoctoral research grant SFRH/BPD/26064/2005 (L. Rodrigues).

Requests for reprints: Ligia Rodrigues, Institute for Biotechnology and Bioengineering, Centre of Biological Engineering, Campus de Gualtar, 4710-057 Braga, Portugal.

Phone: 351-2536-04400; Fax: 351-2536-78986. E-mail: 1rmr@deb.uminho.pt.

Copyright 2007 American Association for Cancer Research.

doi:10.1158/1055-9965.EPI-06-1008
Serum biomarkers are produced by body organs or tumors, and when detected in high amounts in the blood, can be suggestive of tumor activity. These markers are nonspecific for cancer and can be produced by normal organs as well. Most biomarkers are used infrequently for screening purposes. They are more often used to evaluate, treatment effects or to assess the potential for metastatic disease in patients with established disease. In this context, osteopontin, a phosphorylated glycoprotein found in all body fluids, extracellular matrix (ECM) components, and the proteinaceous matrices of mineralized tissues $(23,24)$, also constitutes a possible biomarker. Osteopontin was found to be overexpressed in the tumors and serum of women with ovarian cancer and was correlated with progression $(25,26)$. Recent studies have shown that the overexpression of osteopontin was also related with breast cancer evolution and metastasis (23); therefore, there is a potential utility for osteopontin in monitoring disease status in patients with breast cancer.

This review aims to provide an overview of the characteristics, functions, and mechanisms of interaction of osteopontin that could be further exploited in developing its value as a breast cancer biomarker, either to provide important diagnosis information, to evaluate treatment effects, or to assess the potential for metastatic disease in patients.

\section{The Occurrence of Osteopontin in Normal Human Tissues}

In human tissues, osteopontin has been found to be produced by epithelial cells of the gastrointestinal, urinary and reproductive 
tracts, the gall bladder, pancreas, lung bronchi, lactating breast, salivary glands, and sweat ducts (27). Osteopontin was localized to the luminal surfaces in these sites, as well as in human secretions including blood, milk $(28,29)$, and urine (30). Overall, these findings suggested that osteopontin might have a protective role in interactions between epithelial surfaces and the external environment.

In milk, osteopontin is likely to have a physiologic role (29), as it was noticed that milk is a rich source of the protein. Cell growth, differentiation, and a high degree of tissue remodeling occurs during various stages in the mammary gland. During pregnancy and lactation, these processes ensure the establishment of the spatial relations between stromal and epithelial cells, and the organization of the latter into a branched tree of ducts and terminal alveoli. The highly metabolic active epithelial cells lining the ducts rest on a basal membrane of collagen and other ECM proteins, and signals from the ECM to the cells are important for cell differentiation and milk secretion (31). The description of expression and regulation of osteopontin mRNA in the developing mammary gland has been carefully described in mouse by several researchers (32-34). In vitro experiments with mammary epithelial cells transfected with osteopontin antisense mRNA show the same characteristics as transgenic epithelial cells in vivo. The transfected cells tested positive for matrix metalloproteinase2/procollagenase activity, whereas the control cells did not; hence, up-regulation of matrix metalloproteinase-2 and downregulation of osteopontin seem to be partly responsible for abnormalities in the mammary gland. Possibly, matrix metalloproteinase-2 and osteopontin compete for integrin-binding on cells, and binding of osteopontin may induce normal cell differentiation, whereas binding of matrix metalloproteinase-2 induces undesired tissue degradation (34-36).

In bone, osteopontin is produced by the matrix-synthesizing osteoblasts at the mineralization front and by bone-resorbing osteoclasts (37-39). The osteopontin in bone is mainly localized to the cement lines and surfaces of mature bone trabeculae (40). Osteopontin preferentially accumulates at cell-matrix and matrix-matrix interfacial structures in bone. Hence, osteopontin has multiple presumed functions, including the attachment of osteogenic cells to the bone matrix, control of mineralization (41-43), coupling of bone formation, and resorption $(44,45)$. Moreover, osteopontin is expected to add physical strength to the ECM, as it can be cross-linked by transglutaminase to various matrix proteins, including collagen (46).

Besides epithelial and bone cells, osteopontin is also produced by activated macrophages and lymphocytes (47-51), as well as kidney tubule cells, arterial endothelial and smooth muscle cells, cells of the inner ear (38), fibroblastic cells in embryonic stroma, and in wound healing sites (52).

\section{The Structure of Osteopontin}

Osteopontin was identified, together with bone sialoprotein, as a major sialoprotein in the mineral ECM of bone (53-56). The name "osteopontin" was introduced to reflect the potential of the bone protein to serve as a bridge between cells and hydroxyapatite through RGD (arginine-glycine-aspartate motif) and polyaspartic acid motifs discovered in the primary sequence of the protein (39). However, the same gene product was identified as a putative lymphokine produced by activated lymphocytes and macrophages and called Etr-1 (early T lymphocyte activation gene 1; ref. 47); and thus, a more general pattern of expression for osteopontin emerged. Accordingly, secreted phosphoprotein I was introduced as an alternative name, to reflect the broader functional role of this protein, and in some genomic contexts, represents its "official" name $(57,58)$. Nevertheless, the name osteopontin has largely been retained, in keeping with the nomenclature used for the human gene (59).
The amino acid sequence of osteopontin is nowadays available for several species, i.e., rat (39), mouse (60), human (61), pig (62), rabbit (63), and cow (64). The referenced mammalian osteopontin sequences are identical in $-33 \%$ of the residues, and in addition, many similar amino acids are conserved between the sequences. Identical residues are scattered in clusters. More specifically, the larger clusters are located in the hydrophobic leader sequence (the first 16 residues), in a potential site for $\mathrm{N}$-linked glycosylation, and in several sites for $O$-linked glycosylation and phosphorylation. A stretch of consecutive aspartic acid residues was also found in all species, as well as a cell attachment RGD motif almost immediately followed by a thrombin cleavage site.

Generally, osteopontin is extremely hydrophilic with a low isoelectric point (3.5) and displays an unusual amino acid composition with 42 serine, 48 aspartic acid, and 27 glutamic acid residues, together constituting almost half the residues in human osteopontin (298 residues; refs. 65, 66). It is important to notice that 27 out of the 42 serine residues are phosphorylated (67).

When purified and isolated in solution, osteopontin was found to be flexible along its entire length and to have no significant regions that persist in a single structural environment for more than a few milliseconds (68). That a protein is completely flexible in solution does not mean that it will always remain so. Portions of this protein that strongly interact with other proteins (such as factor $\mathrm{H}$ and the $\alpha_{\mathrm{v}} \beta_{3}$ or other integrin structures and CD44 for osteopontin) will almost certainly adopt specific structures in relation to their binding partners (68).

The conservation among mammalian species of certain residues is presumably indicative of the functions osteopontin performs (38). For instance, osteopontin has been found to play a role in bone mineralization both due to its characteristic amino acid composition and interaction with integrin receptors on cells lining these surfaces $(39,69)$. The RGD motif that is particularly exposed in the osteopontin molecule represents a major, although not unique, binding ligand for the family of integrin receptors, and was found to be involved in cell attachment, cell migration, and intracellular signaling (70).

\section{Osteopontin Gene Expression and Regulation}

Genes encompassed within a $600 \mathrm{~kb}$ region on human chromosome 4 encode several noncollagenous bone and dentin proteins (Fig. 1). They include osteopontin, bone sialoprotein,

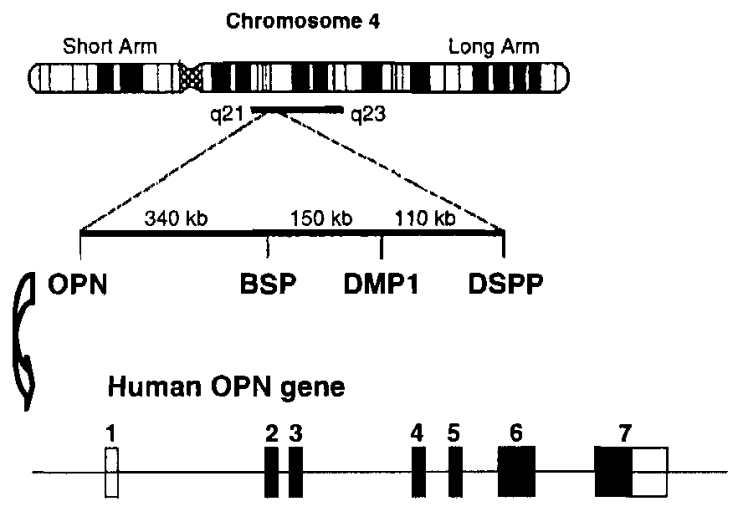

Figure 1. Chromosomal location of the SIBLING genes and gene structure of human osteopontin. The gene location of human osteopontin has been mapped to the long arm of chromosome 4, close to the bone sialoprotein (BSP), dentin matrix protein I (DMPI), and dentin sialophosphoprotein (DSPP) genes. Exons are boxed; filled boxes, coding regions; open boxes, untranslated regions. Adapted from refs. $(73,200,201)$. 
dentin matrix protein I, and dentin sialophosphoprotein, all of which have been categorized as members of the small integrinbinding ligand $\mathrm{N}$-linked glycoprotein (SIBLING) familyrelated proteins (68). The four proteins are somewhat similar being secreted, sialylated, phosphorylated, and acidic in nature. The SIBLING family is the result of duplication and a subsequent divergent evolution of a single ancient gene (68). The primary sequences of the proteins, however, do not show homology and these are therefore not the basis for calling them a related family (68). Rather, the exon-intron boundaries and the similar properties of the individual exons define the SIBLING family.

Osteopontin is encoded by a single copy gene located on the human chromosome 4 (71), the mouse chromosome 5 (57), and the pig chromosome 8 (72). The gene structure of human osteopontin is presented in Fig. 1, and a similar structure with seven exons and six introns is seen in the genes encoding osteopontin from other species. Codon triplets are not interrupted by introns, and consequently, exon skipping will not affect the codon triplets in the remaining exons. The human gene sequence spans $\sim 9 \mathrm{~kb}$ and the open reading frame consists of 942 nucleotides from the start codon (in exon 2) to the stop codon (in exon 7; ref. 73).

The predicted molecular weight of a protein translated from human osteopontin mRNA is $35 \mathrm{kDa}$ (39). The $5^{\prime}$-untranslated region includes exon 1., which starts with a transcription initiation site (AGC), whereas the 3'-untranslated region consists of the last part of exon 7, which includes three potential polyadenylation attachment signals (AATAA; refs. $61,71,73)$. Exon 2 encodes the signal peptide and the first two amino acids in the mature protein; exons 3 and 5, the two characteristic Ser-Ser-Glu-Glu phosphorylation sequences; exon 4, the two transglutaminase-reactive glutamine residues; and exon 6, the aspartic acid-rich sequence. Exon 7 is the largest exon encoding approximately half of the proteins including the RGD motif and the central thrombin cleavage site.

The expression of osteopontin is induced by many factors, e.g., tumor promoters and chemical agents, acting on specific cell types and through different signaling pathways. In most of the studies reported, control is exerted on the level of transcription (70). The promoter sequence of osteopontin provides clues for understanding the molecular basis of transcriptional regulation. Analyses of the osteopontin promoters have uncovered many potential sites for transcription factor interactions $(72,73)$, and a still increasing number of transcription factors have been shown to be directly implicated in osteopontin transcription. Among others, these include progesterone, glucocorticoids, $1 \alpha 25$-dihydroxyvitamin $D_{3}$, and basic helix-loop-helix proteins, such as activator protein-1. Activator protein-1, for example, interacts with a highly conserved enhancer-like element present in many viral and cellular genes, including the osteopontin gene. Collectively, these genes are controlled by the Fos and Jun family of oncoproteins, and consequently, osteopontin is believed to be an effector of activated oncogenes functioning to facilitate tumor growth and metastasis (70).

The murine osteopontin promoter sequence contains a rasactivated enhancer, which is believed to be partly responsible for the increased transcription of osteopontin observed in rasactivated cell lines (74). Induction of osteopontin transcription and tumorigenic transformation by $12-0$-tetradecanoylphorbol-13-acetate in a mouse epidermal cell line (75) suggests the existence of 12-O-tetradecanoylphorbol-13-acetate-responsive elements in the osteopontin gene as well. As for viral regulation of osteopontin, $\mathrm{v}$-Src, which is a viral oncogene produced by the Rous sarcoma virus, is known to stimulate the activity of the osteopontin promoter in mice (76).

The active metabolite of vitamin D, 1 $\alpha 25$-dihydroxyvitamin $D_{3}$, also regulates osteopontin expression in mouse epidermal
Table 1. Osteopontin receptors and receptor-binding motifs

\begin{tabular}{|c|c|c|c|}
\hline Receptor & Name & Motif & Reference \\
\hline Integrin & $\begin{array}{l}\alpha_{v} \beta_{3} \\
\alpha_{v} \beta_{1} \\
\alpha_{v} \beta_{5} \\
\alpha_{5} \beta_{1} \\
\alpha_{8} \beta_{1} \\
\alpha_{4} \beta_{1} \\
\alpha_{9} \beta_{1}\end{array}$ & $\begin{array}{l}\text { RGD } \\
\text { RGD } \\
\text { RGD } \\
\text { RGD } \\
\text { Unknown } \\
\text { SVVYGLR } \\
\text { SVVYGLR } \\
\text { (NH } \text {-terminal thrombin }_{\text {cleaved fragment) }}\end{array}$ & $\begin{array}{l}(44) \\
(202) \\
(202) \\
(203) \\
(85) \\
(204) \\
(93)\end{array}$ \\
\hline Nonintegrin & $\begin{array}{l}\text { CD44 } \\
(\text { v6-10) }\end{array}$ & Non-RGD & $(97-99)$ \\
\hline
\end{tabular}

NOTE: RGD, Arg-Gly-Asp motif; SVVYGLR, Ser-Val-Val-Try-Gly-Leu-Arg motif; CD44 (v6-10), CD44 variants, isoforms 6-10. Except for $\alpha_{9} \beta_{2}$, all integrins bind the uncleaved osteopontin and an $\mathrm{NH}_{2}$-terminal thrombin-cleaved fraginent, which contain the RGD and SVVYGLR sequences. Integrin $\alpha_{9} \beta_{7}$ only binds the $\mathrm{NH}_{2}$-terminal thrombin-cleaved fragment.

cells. However, the induction of osteopontin synthesis and secretion is not correlated with the transformation of the cells as in the case of 12-O-tetradecanoylphorbol-13-acetate stimulation (75). In addition, vitamin D also influences osteopontin levels in osteoblasts, and several vitamin D response elements have been identified in the mouse, chicken, pig, and human osteopontin genes. Moreover, it has been shown that vitamin D not only regulates osteopontin at the transcriptional level, but also seems to modulate the phosphorylation state of osteopontin because vitamin D-stimulated osteoblasts secrete a nonphosphorylated form of the protein (77).

\section{Osteopontin Metabolism and Receptors}

As described above, osteopontin is expressed by a variety of cells and is involved in various processes mediated by receptor interactions (38). Osteopontin is regarded as a molecule that mediates cell-matrix and cell-cell communication, and in many cases, this communication results in the adhesion or targeted migration of cells (78). The interaction between osteopontin and cells is mediated by specific receptor-binding motifs in the osteopontin sequence and receptors on the cell surface (Table 1). Like other proteins in the ECM (such as collagen, fibronectin, vitronectin, laminin, and others) osteopontin exists both as an immobilized ECM molecule in mineralized tissues and as a cytokine in body fluids containing the RGD sequence, which facilitates RGD-dependent interactions with integrin receptors and mediates cell attachment/signaling $(38,79)$. RGD-independent interactions with both integrin and nonintegrin receptors have also been shown (70).

Integrins are transmembrane, dimeric proteins consisting of $\alpha$ and $\beta$ subunits. There are multiple forms of both subunits and each heterodimer can bind a wide variety of ligands with which a cell may come in contact. Ligand binding to integrins could induce clustering and activation of the focal adhesion complex, which includes a number of regulatory and structural proteins, such as focal adhesion kinase, Src, and cytoskeletal proteins. There is evidence that activation of different components of the focal adhesion complex could in turn activate a number of different signal transduction pathways, affecting cellular properties including adhesion, migration, proliferation, and survival (80).

Osteopontin has been shown to interact with a number of different integrins via the RGD sequence, including $\alpha_{v} \beta_{3}, \alpha_{v} \beta_{1}$ and $\alpha_{v} \beta_{5}(38,81,82)$. More recently, additional integrins have been found to interact with osteopontin, including $\alpha_{4} \beta_{1}$ (83), $\alpha_{9} \beta_{1}(84)$, and $\alpha_{8} \beta_{1}(85)$.

The best characterized osteopontin receptor is the $\alpha_{v} \beta_{3}$ integrin, which facilitates RGD-mediated osteopontin adhesion 
to osteoclasts $(44,81)$, smooth muscle cells $(49,86)$, and tumor cells $(87,88)$. Close to the RGD sequence, a site for thrombin cleavage is conserved in all known osteopontin species $(67,89$, 90 ). The susceptibility of osteopontin to thrombin cleavage opens the possibility that osteopontin may be cleaved during the course of blood coagulation, and in tissues and fluids exhibiting thrombin-like proteolytic activity. Interestingly, several studies have provided information suggesting that thrombin-cleaved osteopontins exist side-by-side with the fulllength protein in vivo (38). It seems to be an important characteristic of the protein because cleavage products have been observed in rat plasma and rat tumors (28), human milk (89), and pig bone (54). Fragments of osteopontin originating from either unknown or other proteolytic activities have also been identified in human milk (67) and in human uterus (91). Functionally, fragments of osteopontin produced by thrombin cleavage amplify the effects of the full-length protein (92). For example, a variety of human cell lines exhibit more extensive cell attachment and spreading on thrombin-cleaved osteopontin compared with uncleaved osteopontin (92).

The receptor on the cells mediating the attachment is the $\alpha_{v} \beta_{3}$ integrin, introducing this receptor as a major functional receptor for thrombin-cleaved osteopontin. The cleavage of osteopontin may change the conformation of the molecule, more specifically, the conformation of the sequence around the RGD motif, and thereby affect the binding to the $\alpha_{\mathrm{v}} \beta_{3}$ integrin by allowing greater accessibility to the receptor (92). The RGD motif is contained in the $\mathrm{NH}_{2}$-terminal fragment of thrombincleaved osteopontin and it is this fragment that promotes a stronger response (ref. 87; Fig. 2).

Likewise, the SVVYGLR sequence is located in the $\mathrm{NH}_{2}$ terminal fragment (Fig. 2), and when osteopontin is cleaved by thrombin, this sequence and the RGD motif are exposed. Consequently, RGD- and SVVYGLR-binding integrins are likely to compete for osteopontin binding, however, the consequences of this competition have not been fully explored (93).

The CD44 family includes multiple protein isoforms, encoded by a single gene and generated by alternative splicing, and several of the isoforms have been shown to be overexpressed in malignant cells (94-96). CD44 is a major cell surface receptor for hyaluronate, and various forms of CD44 could also bind to osteopontin $(97,98)$.

Tumor cells are stimulated to spread following this interaction, however, this phenotype also seems to involve the $\beta_{1}$ integrin subunit (98). Osteopontin and CD44 interactions inhibit the expression of interleukin- 10 by macrophages (50) and are possibly involved in the formation of metastases $(99,100)$.

\section{Osteopontin and Malignancy}

Several studies have described a link between osteopontin and cancer in the past years. The first evidence of this link was reported by Senger and coworkers, who described a transformation-specific secreted phosphoprotein produced by a

\begin{tabular}{|llll}
\multicolumn{4}{c}{ Thrombin } \\
\hline \multicolumn{4}{c}{143} \\
\hline
\end{tabular}

Figure 2. Thrombin cleavage of human osteopontin. Thrombin cleavage at $\mathrm{Arg}^{152}-\mathrm{Ser}^{153}$ generates an $\mathrm{NH}_{2}$-terminal fragment with the RGD and SVVYGLR sequences at the carboxyl-terminal. Both of these motifs are recognized by integrin receptors as described in the text. number of transformed cell lines in culture $(89,101,102)$. Afterwards, similar properties were attributed to a protein isolated from bone that was named osteopontin $(55,56,103)$. This protein was sequenced by Prince (103) and several structural features, such as the presence of the RGD motif, were elucidated and discussed providing evidence for some of its functions. Subsequently, Smith and Denhardt (104) cloned a cDNA named " $2 \mathrm{ar}^{\prime}$ which was inducible by tumor promoter treatment of murine JB6 epidermal cells. Ultimately, Craig et al. (105) showed that the bone-derived osteopontin was the same as the protein encoded by the 2ar clone.

The association of osteopontin with malignancy was also supported by the fact that a ras-transformation of nontumorigenic NIH 3T3 cells was shown to confer them a metastatic ability (106). Moreover, osteopontin gene expression was found to be induced in these cells, then pointing to a direct relationship between osteopontin expression and the acquisition of the metastatic phenotype by the cells (107). A novel rasactivated enhancer was later identified in the osteopontin promoter (74).

Furthermore, increasing levels of osteopontin expression have also been found in multistage carcinogenesis in mouse skin (108). Taken together, these experimental studies strongly suggest that osteopontin may play a role in tumor progression and metastasis.

\section{The Role of Osteopontin in Cancer}

The roles of osteopontin in many of its diverse physiologic settings have been discussed in a number of recent reviews. For example, the role of osteopontin in inflammation and immune function have been reviewed by Weber and Cantor (78), Uede et al. (109), and Giachelli and Steitz (45), in mineralized tissues by Denhardt and Noda (70), and in vascular tissue by Ramos (110). A functional role for osteopontin in tumor progression and malignancy has been claimed by several researchers. Multiple and complex mechanisms are involved in the role of osteopontin in cancer, including interactions with cell surface receptors, growth factor/receptor pathways, and proteases. The interactions of osteopontin with various cell surface receptors could induce the activation of various signal transduction pathways, resulting in changes in the expression of a series of genes, the proteins of which contribute to altered cell behavior, including migration and invasion. These effects of osteopontin likely vary between cell types, depending for example on which integrins are expressed and which signal pathways can be activated. There is compelling evidence that soluble osteopontin could, in a variety of situations, help cells survive an otherwise lethal insult. Remarkably, this survival signaling is mediated by receptors that are generally considered to be receptors for ECM components. Denhardt and coworkers suggest that osteopontin delivers an antiapoptotic "ECM-like" signal via multiple ligand-receptor interactions to cells, both adherent and nonadherent (79).

Cell Surface Receptors and Osteopontin. A variety of integrins have been found to be expressed by tumor cells and, depending on the degree of the tumor differentiation, some integrins may be up-regulated or down-regulated (111). The overexpression of integrins is thought to cause constitutive activation of signaling pathways leading to increased growth of tumor cells (1.12-114).

Particularly, the $\alpha_{v} \beta_{3}$ integrin has been related to some aspects of malignancy and metastasis $(112,115,116)$. Recently, a highly tumorigenic, metastatic breast cancer cell line (MDAMB-435) was found to use the $\alpha_{v} \beta_{3}$ integrin for migration towards osteopontin, whereas two nonmetastatic breast cancer cell lines (21PT and 21NT) were found to use $\alpha_{v} \beta_{1}$, and $\alpha_{v} \beta_{5}$ integrins (117). Additionally, a coordinated regulation of 
osteopontin and $\alpha_{\mathrm{v}} \beta_{3}$ integrin has been found in some tissues $(86,118)$. The expression of $\alpha_{v} \beta_{3}$ integrin has also been linked to breast cancer progression through an interaction with protein kinase $C-\alpha$ activity. Using highly metastatic MCF-7 human breast cancer cells transfected to overexpress protein kinase $C-\alpha$, Carey and coworkers (119) found that $\alpha_{v} \beta_{3}$ expression was modulated by increased protein kinase $C-a$ activity. The same cells were used to investigate the integrinmediated suppression of apoptosis (120) and it was found that tumor cells capable of binding osteopontin via the $\alpha_{v} \beta_{3}$ integrin may have a survival advantage.

As mentioned previously, osteopontin could also bind nonintegrin cell surface receptors, such as CD44 (38, 97, 98, $100,121)$. The osteopontin and CD44 interactions could as well be mediated through integrins, as there is some evidence that osteopontin binding by CD44 variants and $\beta 1$-containing integrins could cooperate to promote cell spreading and migration (98). Fujisaki and colleagues (122) proposed a mechanism for the adhesion and migration of colorectal carcinoma cells that describes CD44 induction of integrin expression, and function by both a direct pathway and also via hepatocyte growth factor (HGF) and its receptor (c-Met). This may represent an alternate pathway through which CD44 signals to activate integrin function, aiding in the adhesion and migration of tumor cells.

Growth Factor Receptor Pathways and Osteopontin. Osteopontin transcription may be activated by the ras oncogene (74), and plays a key role in neoplastic transformation, metastasis (24), and cancer progression (123). Osteopontin is usually absent or expressed at a low level in normal tissues but is up-regulated in certain preneoplastic and neoplastic epithelia $(28,123,124)$, including that of the breast (125). Transfection of an expression vector for osteopontin induces malignant transformation and induction of metastasis in a benign rat mammary epithelial cell line (126), whereas transfection of osteopontin antisense cDNA inhibits these processes in a cell line already overexpressing osteopontin $(127,128)$. These results suggest that osteopontin overexpression may represent a key molecular event in tumor progression and metastasis, particularly that of the breast. Unlike many proto-oncogenes activated by a gain of function mutation, osteopontin is not typically mutated during stepwise tumorigenesis (24). Instead, various responsive elements in its promoter regulate osteopontin expression for its diverse physiologic roles (129-132), and it is presumably these elements that allow the overexpression of osteopontin in certain cancers.

Interactions of osteopontin with growth factor receptor pathways may influence tumor cell behavior. Tumor cell migration can be influenced by HGF and its receptor, Met. In Webb and coworkers' study (133), HGF and Met receptor signaling was associated with a transformed phenotype in rastransformed NIH $3 \mathrm{~T} 3$ cells. Furthermore, the HGF pathway was recently reported to affect the adhesion and invasion of cancer cells (134).

The correlation between osteopontin and the HGF/Met pathway was further explored in breast cancer models, and a synergistic relationship between osteopontin and HGF in inducing cell migration was found (117). Additionally, integrin-mediated induction of cell migration in response to osteopontin was accompanied by an initial increase in Met kinase activity, followed by an increase in Met mRNA and protein expression levels (117).

Cell Proteases and Osteopontin. Several studies have described the interactions between integrins and other membrane receptors, such as urokinase-type plasminogen activator (UPA) and its receptor (UPAR), which have been implicated in tumor metastasis. Proteolytic enzymes are believed to contribute to metastasis and tumor growth in several ways (135-138), i.e., via degradation of ECM components and facilitating migration and invasion, or by activation of other proteases.

Osteopontin, either transfected into breast cancer cell lines or added exogenously to them, was shown to increase both the invasiveness of the cells and uPA expression (139), possibly due to cell surface interactions between osteopontin-binding integrins (e.g., $\left.\alpha_{v} \beta_{5}\right)$ and uPA/uPAR. It has been shown that uPARbound $\mathrm{uPA}$ is required for $\alpha_{\mathrm{v}} \beta_{5}$ integrin-mediated cell migration of human pancreatic carcinoma cells (140). Likewise, Carriero and coworkers (141) have shown that $\alpha_{v} \beta_{5}$ integrin interaction with UPAR promotes the migration of human breast cancer (MCF-7) cells. Thus, osteopontin may increase the malignant abilities of cancer cells in part via integrin-mediated induction of UPA and interactions with uPA/uPAR. On the other hand, down-regulation of UPAR has been linked to the dormancy of tumor cells in vivo (142). Accordingly, there is a possibility that binding and activation of specific cell surface integrins by osteopontin could take tumor cells out of dormancy by promoting interactions between integrin and UPAR.

In other cell types, osteopontin has also been found to induce the expression and activity of other proteases such as members of the metalloproteinase family, which can contribute to metastasis via multiple mechanisms $(135-137,143,144)$. These studies provide evidence that osteopontin may play a critical role in tumor cell regulation of matrix proteolysis, e.g., in invasion and metastasis.

The Role of Osteopontin in Angiogenesis. Angiogenesis is the formation of new blood vessels that allows for sustained growth and metastasis of tumor cells. This complex process requires the coordinated action of growth factors and their receptors, extracellular proteins, adhesion molecules, and proteolytic enzymes (145-148).

Some studies have reported an implicated osteopontin in angiogenesis, nevertheless, many of the results remain circumstantial and further clarification on the details of this possible role are required. The association of osteopontin with this process is a consequence of its ability to bind the $\alpha_{v} \beta_{3}$ integrin, which in turn, is a marker of angiogenesis and is expressed by neovascular endothelial cells (86).

Brooks and coworkers $(149,150)$ found that $\alpha_{\mathrm{v}} \beta_{3}$ integrin expression increases during angiogenesis, and that by blocking this integrin, angiogenesis can be inhibited. Moreover, a role for the $\alpha_{v} \beta_{3}$ integrin in signaling the survival and differentiation of vascular cells during angiogenesis in vivo was shown. Additionally, this integrin and osteopontin have been found to be significant in vascular repair and regeneration, as osteopontin can stimulate the adhesion and migration of endothelial cells, and $\alpha_{v} \beta_{3}$ and osteopontin are simultaneously upregulated following vascular damage (86).

A role in protecting endothelial cells from apoptosis has been reported for osteopontin, possibly via the activation of nuclear factor $\kappa \mathrm{B}$ (151). Furthermore, osteoprotegerin expression, a tumor necrosis factor receptor, induced by the interaction between osteopontin and $\alpha_{v} \beta_{3}$, has been found to protect endothelial cells from apoptosis (152). The increased endothelial cell survival promoted by osteopontin supports the association of osteopontin with malignancy. In addition osteopontin contributes to angiogenesis through effects on the expression of vascular endothelial growth factors (153). Endotheljal cell migration is stimulated by the cooperation between the vascular permeability factor (vascular endothelial growth factor) with osteopontin and $\alpha_{v} \beta_{3}$ integrin. Although the expression of vascular endothelial growth factor, osteopontin, and integrin $\alpha_{v} \beta_{3}$ has been related with angiogenesis in glioblastomas (154), and has been associated with poor prognosis in patients with in stage I lung adenocarcinoma (155), any clinical role for osteopontin in angiogenesis remains to be clarified. 
The Role of Osteopontin on Tumor Cell Survival. Besides the possible contributions of osteopontin to the metastatic phenotype presented above, osteopontin has also been shown to exert a role in cancer by enhancing the survival of several cell types, through interactions with various host defense systems. The affected cells include tumor cells, vascular endothelial cells, or tumor-infiltrating cells of the immune system, and these effects might have conflicting influences on the malignancy and growth of a tumor. An example may be the case when osteopontin indirectly favors the survival of tumor cells via macrophage liaison. Interactions between osteopontin and $\alpha_{\mathrm{v}} \beta_{3}$ integrins were found to affect the nitric oxide production by macrophages $(72,156)$. Produced by a number of different cell types, including activated macrophages and vascular endothelial cells, nitric oxide can act as a powerful signaling molecule, as well as causing localized cytotoxicity. Although nitric oxide is effective against microbial invaders and tumor cells, osteopontin was found to inhibit its synthesis (157-161), and therefore, plays an important role in tumor defenses against the immune system $(156,157)$. Moreover, nitric oxide has been reported to have tumorpromoting effects, however, its role in malignancy is far from being fully understood (162-164). Osteopontin production by tumor cells could promote tumor growth and metastasis by protecting them from nitric oxide $(156,158)$. In this way, osteopontin-producing tumor cells would be favored for growth, relative to tumor cells that did not produce osteopontin. Nevertheless, tumor cells that secrete osteopontin might promote their own destruction by attracting host inflammatory cells, such as macrophages that can be cytotoxic to the tumor cells $(49,78)$. Thus, the interactions of osteopontin with various aspects of host defense systems, might in some cases, lead to opposing effects on tumor growth and survival.

\section{The Significance of Osteopontin in Human Cancer}

At present, it is fully accepted that osteopontin expressed by tumor cells alters their malignant properties, specifically by affecting their ability to grow, invade, and metastasize. However, as osteopontin is known to be expressed in both normal and malignant tissues, an elucidation of its significance in human cancer is required. Recent studies suggest that osteopontin levels in the blood or tumors of patients with cancer may provide useful clinical information on patient prognoses.

The Occurrence of Osteopontin in Human Tumors. The expression of osteopontin in human tumors was initially shown in several human carcinomas by Brown and coworkers (27). Considerably higher levels of osteopontin mRNA were found in all tumors screened (colon, breast, lung, stomach, endometrium, and thyroid) as compared with corresponding normal tissues. Nevertheless, two examples of benign tumors (colonic adenomas from a patient with familial polyposis and a uterine leiomyoma) showed similar osteopontin mRNA levels compared with normal tissues. Moreover, cells that were positive for osteopontin transcripts were most abundant at the advancing edge of tumors and near areas of necrosis. Supporting these findings, other studies also showed osteopontin mRNA and protein overexpression in several cancers, such as lung (165), breast (166) and esophageal cancers (167), gastric cancers (168), prostate cancers (169), and gliomas (170). Osteopontin expression in tumors has been identified by immunohistochemistry, specifically localized in the macrophages in some tumors, and in both tumor cells and macrophages in others (171).

The significance of osteopontin from different sources within a tumor is poorly understood, although prognostic studies in breast cancer (166) suggest that this may be important for the biology of the tumor. Several researchers have shown the presence of osteopontin in microcalcifications in breast tumor tissues $(172,173)$ and in ectopic calcification in other tumors, such as serous papillary cystadenocarcinoma of the ovary, meningiomas, papillary carcinoma of the thyroid, and pilomatricomas (174-176)

Tumor Aggressiveness and the Occurrence of Osteopontin in Primary Tumors. Osteopontin expression in some tumors that can be detected in both tumor cells and several host cells has triggered an emerging interest in its potential usefulness as a marker of tumor aggressiveness and patient prognosis.

The potential to predict a poor patient prognosis based on osteopontin overexpression was first reported by Chambers and coworkers (165). Osteopontin expression was followed both in lung tumor samples and normal tissue. The results pointed to osteopontin expression in tumor samples and negligible expression in normal tissues. The osteopontin protein was localized by immunohistochemistry to both lung tumor cells and tumor-associated macrophages. The relation of osteopontin expression in tumors and poor patient survival was found to have statistical significance. Results obtained by Shijubo and coworkers (155) also suggest that osteopontin overexpression in lung tumors might be an indicator of poor prognosis.

The association of osteopontin with breast tumor progression was studied by Tuck and coworkers (177) using samples from a patient who had bilateral mammary carcinomas of similar histology that later developed metastatic recurrence. The tumor in the right breast had spread to the lymph nodes, whereas the left-sided tumor had not. The patient later developed right-sided local recurrence followed by widespread metastatic disease. The findings from this case suggest that osteopontin, both in tumor cells and in plasma, may be a marker for tumor aggressiveness in breast cancer, and elevated levels in a primary tumor may predict for future development of metastasis. To confirm these results, the same group studied the expression of osteopontin mRNA and protein in the tumors of 154 women with lymph nodenegative breast cancer (166). It was found that immunohistochemical staining for osteopontin protein was increased in the infiltrating macrophages and lymphocytes of $70 \%$ of the tumors, a proportion too high to be discriminatory in predicting patient survival. However, osteopontin staining localized specifically to the tumor cells was shown in $26 \%$ of the tumors. Osteopontin mRNA was detected in tumor cells and in inflammatory cells, indicating that both cell types could be a source for osteopontin detected within tumors. This study supports the idea that osteopontin levels within tumor cells may be a useful predictor of patient outcome in breast cancer, and also that osteopontin may play a functional role in tumor progression and aggressiveness. A correlation between osteopontin expression and an increased invasiveness or metastatic potential has also been reported in other human tumors $(168,170)$.

Osteopontin expression was detected in prostate cancer, being expressed by the tumor cells themselves $(169,178)$. Nevertheless, there is some controversy over whether osteopontin expression was associated with malignancy of the prostate carcinoma (169) because in one study, evidence was also found for the overexpression of osteopontin in benign glandular hyperplasia of the prostate (178). Likewise, in ovarian cancer, the role of osteopontin in malignancy is unclear, and although some studies point to a positive correlation of osteopontin with ovarian cancer progression (26), others show contradictory conclusions depending on the tumor-malignant potential (179). Tiniakos and coworkers found that osteopontin expression was higher in tumors of low malignant potential as compared with benign ovarian tissue; however, invasive carcinomas showed generally lower osteopontin levels (179). Liapis and coworkers (180) discussed 
a possible explanation, as they found that ovarian tumors of low malignant potential underexpress the $\alpha_{v} \beta_{3}$ integrin, to which osteopontin can bind, in comparison with invasive ovarian carcinomas. Therefore, the absence of $\alpha_{\mathrm{v}} \beta_{3}$ integrin expression in tumors of low malignant potential may account for the lack of responsiveness to the malignancy-promoting effects of osteopontin, even in the presence of higher levels of osteopontin. On the other hand, as the primary mechanism of the spreading of ovarian carcinoma is different from other cancers, it is possible that osteopontin plays different roles in cancers that spread by different routes.

The Meaning of Osteopontin in the Blood of Patients with Cancer. Recently, several studies have pointed to the potential of osteopontin to provide clinical information useful in the management of patients with breast and perhaps other cancers. Osteopontin serum levels were found to be increased 4- to 10 -fold in a variety of human disseminated carcinomas, including breast, lung, and prostate $(28,181)$; and these higher levels were correlated with higher tumor grade.

An antigen-capture ELISA, using a combination of mouse monoclonal and rabbit polyclonal antibodies, was developed in order to assess osteopontin blood levels $(182,183)$. This methodology permits quantitative, rapid, and reproducible measurement of osteopontin levels in blood plasma and other fluids. Studies with women volunteers showed that osteopontin levels did not differ between premenopausal and postmenopausal women $(182,183)$. Moreover, it was found that although osteopontin can be hormonally regulated in some tissues $(58,184)$, osteopontin blood levels do not reflect hormonal changes over the menstrual cycle. After establishing the basal levels of osteopontin in healthy women, Singhal and coworkers (184) used the same assay to test for an association between elevated blood osteopontin levels and patient outcome in breast cancer. Plasma osteopontin levels were measured in patients with metastatic breast cancer, control patients (women on follow-up after treatment for primary breast cancer, with no evidence of disease), and healthy patients. Elevated plasma osteopontin was found to be associated with a shorter survival, larger numbers of sites of metastatic involvement, and poorer outcome for women with metastatic breast cancer.

\section{Breast Cancer Biomarkers}

Regardless of the recent spectacular advances in molecular medicine, genomics, proteomics, and translational research, mortality rates for the most prevalent cancers have not been significantly reduced $(14,15,17)$. Some of the best available options to combat cancer include primary prevention, earlier diagnosis, and improved therapeutic interventions. We are now witnessing the development of new drugs against cancer that are based on rational instead of empirical designs. Hopefully, some of these drugs will prove to be more effective at the clinic than older generations of medicines. In terms of primary prevention, we still don't have any robust strategies because although the major mechanisms underlying both cancer initiation and progression are well established, they are extremely complex. These processes are genetic, and epigenetic processes leading to mutations in several genes and alterations in chromosomal structure are likely accompanied by self-perpetuating changes in signal transduction pathways.

One of the best strategies to combat cancer is by early diagnosis and administration of effective treatment (185). Another approach includes close monitoring of the cancer patient after initial treatment (usually surgery) to detect early relapse, and then, additional prescribed therapy. A third valuable approach would be the stratification of patients into subgroups that respond better to different types of treatment (individualized therapy). Medical imaging and serum or tissue biomarkers are valuable tools for monitoring these patients in order to optimize clinical outcomes.

A handful of cancer biomarkers, such as prostate-specific antigen, breast and ovarian cancer susceptibility genes (BRCA1 and $B R C A 2$ ) for example, are currently used routinely for population screening, disease diagnosis, prognosis, monitoring of therapy, and prediction of therapeutic response. Nevertheless, it is important to notice that most of the biomarkers used nowadays haven't got adequate sensitivity, specificity, and predictive value for population screening. Biomarkers are clinically recommended mainly for monitoring the effectiveness of therapeutic interventions. Some biomarkers are also invaluable tools for the early diagnosis of cancer relapse, which may trigger additional treatments before the appearance of clinical symptoms. With current cancer biomarkers, much is left to be desired in terms of clinical applicability. We need new cancer biomarkers that will further enhance our ability to diagnose, prognose, and predict therapeutic response in many types of cancer. Because biomarkers can be analyzed relatively noninvasively and economically, it is worth investing in discovering more biomarkers in the future.

Breast cancer statistics show that $>1.2$ million persons will be diagnosed with breast cancer worldwide this year, according to the WHO. According to the American Cancer Society, an estimated 212,920 new cases of invasive breast cancer are expected to occur among women in the U.S. during 2006. As breast cancer is the most frequently diagnosed cancer in women, it is imperative that new alternative tumor markers be developed. Several breast cancer markers have been studied, although just a few proved to be effective $(10,11)$. For example, serum tumor marker levels, such as carcinoembryonic antigen and others, may reflect disease progression and recurrence, but have not proven to be sensitive for early disease detection (186). Recently, mammaglobin and maspin have been described as potential markers of early breast cancer as well as to detect occult metastasis (187-189). Estrogen and progesterone receptors have been used as markers of prognosis and predictors of response to antiestrogen therapy, and are established as a standard of care for patients with breast cancer (190-192). In addition, cell cycle markers (e.g., Ki-67; ref. 193), growth factors and receptors (e.g., HER2; ref. 9), tumor suppressor genes (e.g., p53; ref. 194), and cell adhesion molecules (e.g., E-cadherin and P-cadherin; refs. 195-198) have been studied as possible breast tumor markers. In this context, osteopontin also represents an interesting alternative as a breast cancer marker. Using a cDNA microarray system, it was found that osteopontin was overexpressed in the tumors and serum of women with a recent diagnosis of ovarian cancer (25). Additionally, Kim et al. (26) showed that osteopontin concentrations in plasma were higher in patients with ovarian cancer as compared with healthy controls, or women with benign ovarian disease or other gynecologic cancers, thus an association between levels of osteopontin and ovarian cancer suggest that future research assessing its clinical usefulness would be worthwhile (199).

Recent studies have shown that osteopontin overexpression is also related with breast cancer evolution and metastasis (23); therefore, there is a potential utility of osteopontin in monitoring the disease status of patients with breast cancer.

\section{Conclusions}

A host of interesting advances in molecular medicine, genomics, and proteomics have led to the discovery of several potential tumor markers. This review focuses on the functional roles and clinical significance of osteopontin in cancer and metastasis, and its potential as a biomarker. Osteopontin seems to be more than just a marker of malignancy because this protein may play a functional role in malignant-gene 
expression and/or cancer cell behavior. Multiple and complex mechanisms are involved in the role of osteopontin in cancer, including interactions with cell surface receptors, growth factor/receptor pathways, and proteases; therefore, much remains to be learned about these mechanisms and the functional contributions of osteopontin produced by different cell types in order to establish appropriate antiosteopontin therapeutic strategies. Several possible therapeutic approaches to interfere with the malignancy-enhancing effects of osteopontin, thereby reducing tumor cell growth and metastasis, are being developed. As discussed, one of the best strategies to combat cancer is by early diagnosis and administration of effective treatment. In spite of the number of cancer biomarkers currently used routinely, their usefulness still remains limited due to the lack of adequate sensitivity, specificity, and predictive value for population screening. Additional clinical trials are required to validate the use of biomarkers in order to establish their efficacy and enhance our ability to diagnose, prognose, and predict therapeutic responses. Some studies have established an association between elevated osteopontin levels in patients' tumors or blood with a poor diagnosis; hence, it could represent a tumor marker for use in the breast cancer arena waiting to be fully exploited.

\section{References}

1. Kelloff GJ, Boone $\mathrm{CW}$, Crowell JA, et al. Risk biomarkers and current strategies for cancer chemoprevention. Clin Chem 1996;48:1160-9

2. Henson DE, Srivastava S, Kramer BS. Molecular and genetic targets in early detection. Curr Opin Oncol 1999;11:419-25

3. Baker SG. Identifying combinations of cancer markers for further study as triggers of early intervention. Biometrics $2000 ; 56: 1082-7$.

4. Pepe MS, Etzioni R, Feng Z, et al. Phases of biomarker development for early detection of cancer. J Natl Cancer Inst 2001:93:1054 -61.

5. Sueoka E, Sueoka N, Goto $Y$, et al. Heterogeneous nuclear ribonucleoprotein $\mathrm{B} 1$ as early cancer biomarker for occult cancer of human lungs and bronchial dysplasia. Cancer Res 2001;61:1896-902.

6. Diamandis EP, Yousef GM. Human tissue kallikreins: a family of new cancer biomarkers. Clin Chem 2002;48:1198 - 205.

7. Rosty C, Christa L, Kuzdzal S, et al. Identification of hepatocarcinomaintestine-pancreas/pancreatitis-associated protein I as a biomarker for pancreatic ductal adenocarcinoma by protein biochip technology. Cancer Res 2002;62:1868-75.

8. Korshunov A, Golanov A, Sycheva R. Immunohistochemical markers for prognosis of cerebral glioblastomas. J Neurooncol 2002;58:217-36.

9. Ross JS, Fletcher JA, Linette GP, et al. The HER-2/neu gene and protein in breast cancer 2003: biomarker and target of therapy. Oncologist 2003;8: 307-25.

10. Ross JS, Linette GP, Stec JCE, et al. Breast cancer biomarkers and molecular medicine. Expert Rev Mol Diagn 2003;3:573-85.

11. Ross JS, Linette GP, Stec JCE, et al. Breast cancer biomarkers and molecular medicine: part II. Expert Rev Mol Diagn 2004;4:169-88.

12. Verma M, Wright GI, Jr., Hanash SM, Gopal-Srivastava R, Srivastava S. Proteomic approaches within the $\mathrm{NCl}$ early detection research network for the discovery and identification of cancer biomarkers. Ann N Y Acad Sci 2001;945:103-15.

13. Welsh JB, Sapinoso LM, Su AI, et al. Analysis of gene expression identifies candidate markers and pharmacological targets in prostate cancer. Cancer Res 2001;61:5974-8.

14. Li J, Zhang Z, Rosenzweig J, Wang YY, Chan DW. Proteomics and bioinformatics approaches for identification of serum biomarkers to detect breast cancer. Clin Chem 2002;48:1296-304

15. Srinivas PR, Verma $M$, Zhao $Y$, Srivastava S. Proteomics for cancer biomarker discovery. Clin Chem 2002;48:1160-9.

16. Wulfkuhle JD, Liotta LA, Petricoin EF. Proteomic applications for the early detection of cancer. Nat Rev Cancer 2003:3:267-75.

17. Diamandis EP. Mass spectrometry as a diagnostic and a cancer biomarker discovery tool: opportunities and potential limitations. Mol Cell Proteomics 2004;3:367-78.

18. Sugita M, Geraci M, Gao B, et al. Combined use of oligonucleotide and tissue microarrays identifies cancer/testis antigens as biomarkers in lung carcinoma. Cancer Res 2002;62:3971-9.

19. Beenken SW, Grizzle WE, Crowe DR, et al. Molecular biomarkers for breast cancer prognosis: coexpression of c-erbB-2 and p53. Ann Surg 2001;233:630-8.

20. Fenech $M$. Chromosomal biomarkers of genomic instability relevant to cancer. Drug Discov Today 2002;7:1128--37.

21. Pritzker KPH. Cancer biomarkers: easier said than done. Clin Chem 2002;48: $1147-50$.

22. Srivastava S, Gopal-Srivastava R. Biomarkers in cancer screening: a public health perspective. J Nutr 2002;132:2471-5.
23. Furger KA, Menon RK, Tuck AB, Bramwell VH, Chambers AF. The functional and clinical roles of osteopontin in cancer and metastasis. Curr Mol Med 2001;1:621 - 32 .

24. Weber GF. The metastasis gene osteopontin: a candidate target for cancer therapy. Biochim Biophys Acta 2001;552:61 - 85 .

25. Wong KK, Cheng RS, Mok SC. Identification of differentially expressed genes from ovarian cancer cells by MICROMAX cDNA microarray system. Biotechniques 2001;30:670-5.

26. Kim J-H, Skates SJ, Uede T, et al. Osteopontin as a potential diagnostic biomarker for ovarian cancer. JAMA 2002;287:1671-9.

27. Brown LF, Berse B, Van de Water L, et al. Expression and distribution of osteopontin in human tissues: widespread association with luminal epithelial surfaces. Mol Biol Cell 1992;3:1169-80.

28. Senger DR, Perruzzi CA, Gracey CF, Papadopoulos A, Tenen DG. Secreted phosphoproteins associated with reoplastic transformation: close homology with plasma proteins cleaved during blood coagulation. Cancer Res 1988;48. $5770-4$.

29. Senger DR, Perruzzi CA, Papadopoulos A. Elevated expression of secreted phosphoprotein I (osteopontin, 2ar) as a consequence of neoplastic transformation. Anticancer Res 1989;9:1291-9.

30. Shiraga $H$, Min $W$, Vandusen $W J$, et al. Inhibition of calcium oxalate crystal growth in vitro by uropontin: another member of the aspartic acid-rich protein superfamily. Proc Natl Acad Sci U S A 1992;89:426-30.

31. Russo J, Hu YF, Yang $X$, Russo IH. Developmental, cellular, and molecular basis of human breast cancer. J Natl Cancer Inst Monogr 2000;27:17-37.

32. Rittling SR, Novick KE. Osteopontin expression in mammary gland development and tumorgenesis. Cell Growth Differ 1997;8:1061 -9.

33. Rittling SR, Matsumoto HN, McKee MD, et al. Mice lacking osteopontin show normal development and bone structure but display altered osteoclast formation in vitro. J Bone Miner Res 1998;13:1101-11.

34. Nemir M, Bhattacharyya D, Li X, Singh K, Mukherjee AB, Mukherjee BB Targeted inhibition of osteopontin expression in the mammary gland causes abnormal morphogenesis and lactation deficiency. J Biol Chem 2000;275: 969-76.

35. Brooks PC, Stromblad S, Sanders LC, et al. Localization of matrix metalloproteinase MMP-2 to the surface of invasive cells by interaction with integrin $\alpha v \beta 33$. Cell 1996;85:683-93.

36. Deryugina El, Bourdon MA, Jungwirth $\mathrm{K}$, Smith JW, Strongin AY. Functional activation of integrin $\alpha v \beta 3$ in tumor cells expressing membrane-type 1 matrix metalloproteinase. Int J Cancer 2000;86:15-23.

37. Butler WT. The nature and significance of osteopontin. Connect Tissue Res $1989 ; 23: 123-36$

38. Sodek J, Ganss B, McKee MD. Osteopontin. Crit Rev Oral Biol Med 2000;11: $279-303$.

39. Oldberg A, Franzen A, Heinegard D. Cloning and sequence analysis of rat bone sialoprotein (osteopontin) cDNA reveals an Arg-Gly-Asp cell-binding sequence. Proc Natl Acad Sci U S A 1986,83:8819-23.

40. McKee MD, Farach-Carson MC, Butler WT, Hauschka PV, Nanci A UItrastructural immunolocalization of noncollagenous (osteopontin and osteocalcin) and plasma (albumin and $\alpha 2 \mathrm{HS}$-glycoprotein) proteins in rat bone. J Bone Miner Res 1993;8:485-96.

41. Goldberg HA, Hunter GK. The inhibitory activity of osteopontin on hydroxyapatite formation in vitro. Ann N Y Acad Sci 1995;760:305-8.

42. Nagata T, Bellows CG, Kasugai S, Butler WT, Sodek J. Biosynthesis of bone proteins (SPP-1 (secreted phosphoprotein-1, osteopontin), BSP (bone sialoprotein) and SPARC (osteonectin)) in association with mineralizedtissue formation by fetal-rat calvarial cells in culture. Biochem J 1991;274: $513-20$.

43. Hunter GK, Hauschka PV, Poole AR, Rosenberg LC, Goldberg HA Nucleation and inhibition of hydroxyapatite formation by mineralized tissue proteins. Biochem J 1996;317:59-64

44. Ross FP, Chappel J, Alvarez Jl, et al, Interactions between the bone matrix proteins osteopontin and bone sialoprotein and the osteoclast integrin $\alpha v \beta 3$ potentiate bone resorption. I Biol Chem 1993;268:9901-7.

45. Giachelli CM, Steitz S. Osteopontin: a versatile regulator of inflammation and biomineralization. Matrix Biol 2000;19:615-22.

46. McKee MD, Nanci A. Osteopontin: an interfacial extracellular matrix protein in mineralized tissues. Connect Tissue Res 1996:35:197-205.

47. Patarca R, Freeman GJ, Singh RP, et al. Structural and functional studies of the early $T$ lymphocyte activation 1 (Eta-1) gene. Definition of a novel $T$ celldependent response associated with genetic resistance to bacterial infection. J Exp Med 1989;170:145-61.

48. Patarca R, Saavedra RA, Cantor H. Molecular and cellular basis of genetic resistance to bacterial infection: the role of the early T-lymphocyte activation-1/osteopontin gene. Crit Rev Inmunol 1993;13:225-46.

49. Giachelli CM, Lombardi D, Johnson RJ, Murry CE, Almeida M. Evidence for a role of osteopontin in macrophage infiltration in response to pathological stimuli in vivo. Am J Pathol 1998;152:353-8.

50. Ashkar S, Weber GF, Panoutsakopoulou V, et al. Eta-1 (osteopontin): an early component of type-1 (cell-mediated) immunity. Science 2000;287: $860-4$

51. Santana MA, Rosenstein $Y$. What it takes to become an effector $T$ cell: the process, the cells involved, and the mechanisms. J Cell Physiol 2003;195: $392-401$.

52. Liaw L, Birk DE, Ballas CB, Whitsitt JS, Davidson JM, Hogan BL. Altered wound healing in mice lacking a functional osteopontin gene (spp1). J Clin Invest 1998;101:1468-78. 
53. Prince CW, Oosawa T, Butler WT, et al. Isolation, characterization and biosynthesis of a phosphorylated glycoprotein from rat bone. ] Biol Chem $1987 ; 262: 2900-7$.

54. Zhang Q, Domenicucci C, Goldberg HA, Wrana JL, Sodek J. Characterization of fetal porcine bone sialoproteins, secreted phosphoprotein 1 (SPPI, osteopontin), bone sialoprotein, and a $23-\mathrm{kDa}$ glycoprotein. Demonstration that the 23-kDa glycoprotein is derived from the carboxyl terminus of SPPI. J Biol Chem 1990;265:7583-9.

55. Fisher LW, Hawkins GR, Tuross N, Termine JD. Purification and partia characterization of small proteoglycans I and II, bone sialoproteins I and II and osteonectin from the mineral compartment of developing human bone. J Biol Chem 1987;262:9702-8.

56. Franzen A, Heinegard D. Isolation and characterization of two sialoproteins present only in bone calcified matrix. Biochem J 1985;232:715-24.

57. Fet V, Dickinson ME, Hogan BL. Localization of the mouse gene for secreted phosphoprotein 1 (Spp-1) (2ar osteopontin, bone sialoprotein 1, 44-kDa bone phosphoprotein, tumor-secreted phosphoprotein) to chromosome 5 , closely linked to Ric (Rickettsia resistance). Genomics 1989;5:375 -7

58. Craig AM, Denhardt DT. The murine gene encoding secreted phosphoprotein 1 (osteopontin): promoter structure, activity, and induction in vivo by estrogen and progesterone. Gene 1991;100:163-71

59. Denhardt DT, Lopez CA, Rollo EE, et al. Osteoponyin-induced modifications of cellular functions. Ann N Y Acad Sci 1995;760:127-42.

60. Craig AM, Smith JH, Denhardt DT. Osteopontin, a transformation associated cell adhesion phosphoprotein, is induced by 12-O-tetradecanoylphorbol 13-acetate in mouse epidermis. J Biol Chem 1989;264:9682-9.

61. Kiefer MC, Bauer DM, Barr PJ. The $C D N A$ and derived amino acid sequence for human osteopontin. Nucleic Acids Res 1989;17:3306.

62. Wrana JL, Zhang $Q$, Sodek J. Full length $\mathrm{cDNA}$ sequence of porcine secreted phosphoprotein-I (SPP-I, osteopontin). Nucleic Acids Res 1989;17:10119.

63. Tezuka K, Sato T, Kamioka H, et al. Identification of osteopontin in isolated rabbit osteoclasts. Biochem Biophys Res Commun 1992;186:911-7.

64. Kerr JM, Fisher LW, Termine JD, Young MF. The cDNA cloning and RNA distribution of bovine osteopontin. Gene 1991;108:237-43

65. Mazzali M, Kipari T, Ophascharoensuk V, Wesson JA, Johnson R, Hughes J Osteopontin-a molecule for all seasons. Q J Med 2002;95:3-13

66. Christensen B, Nielsen MS, Haselmann KF, Petersen TE, Sorensen ES. Posttranslationally modified residues of native human osteopontin are located in clusters: identification of 36 phosphorylation and five O-glycosylation sites and their biological implications. Biochem J 2005;390:285-92.

67. Sorensen ES, Hojrup P, Petersen TE. Posttranslational modifications of bovine osteopontin: identification of twenty-eight phosphorylation and three O-glycosylation sites. Protein Sci 1995;4:2040-9.

68. Fisher LW, Torchia DA, Fohr B, Young MF, Fedarko NS. Flexible structure of SIBLING proteins, bone sialoprotein, and osteopontin. Biochem Biophys Res Commun 2001;280:460-5.

69. Hunter GK, Kyle CL, Goldberg HA. Modulation of crystal formation by bone phosphoproteins: structural specificity of the osteopontin-mediated inhibition of hydroxyapatite formation. Biochem ] 1994;300:723-8

70. Denhardt DT, Noda M. Osteopontin expression and function: role in bone remodelling. J Cell Biochem Suppl 1998;30-1:92-102.

71. Young MF, Kerr JM, Termine JD, et al. cDNA cloning, mRNA distribution and heterogeneity, chromosomal location, and RFLP analysis of human osteopontin (OPN). Genomics 1990;7:491-502.

72. Denhardt DT, Guo X. Osteopontin: a protein with diverse functions. FASEB 1993;7:1475-82.

73. Hijiya N, Setoguchi M, Matsuura K, Higuchi Y, Akizuki S, Yamamoto S Cloning and characterization of the human osteopontin gene and it promoter. Biochem J 1994;303:255-62.

74. Guo $X$, Zhang YP, Mitchell DA, Denhardt DT, Chambers AF. Identification of a ras-activated enhancer in the mouse OPN promoter and its interaction with a putative ETS-related transcription factor whose activity correlates with the metastatic potential of the cell. Mol Cell Biol 1995;15:476-87.

75. Chang PL, Prince CW. $1 \alpha, 25$-Dihydroxyvitamin $D_{3}$ stimulates synthesis and secretion of nonphosphorylated osteopontin (secreted phosphoprotein 1) in mouse JB6. Cancer Res 1991;51:2144-50.

76. Tezuka K, Denhardt DT, Rodan GA, Harada S. Stimulation of mouse osteopontin promoter by $\mathrm{v}$-Src is mediated by a CCAAT box-binding factor J Biol Chem 1996;271:22713-7.

77. Safran JB, Butler WT, Farach-Carson MC. Modulation of osteopontin post translational state by $1,25-(\mathrm{OH}) 2$-vitamin $\mathrm{D}_{3}$. Dependence on $\mathrm{Ca}^{2+}$ influx. J Biol Chem 1998;273:29935-41.

78. Weber GF, Cantor H. The immunology of Eta-1/osteopontin. Cytokine Growth Factor Rev 1996;7:241-8.

79. Denhardt DT, Noda M, O'Regan AW, Pavlin D, Berman JS. Osteopontin as a means to cope with environmental insults: regulation of inflammation, tissue remodelling, and cell survival. J Clin Invest 2001;107:1055-61.

80. Newham P, Humphries MJ. Integrin adhesion receptors: structure, function and implications for biomedicine. Mol Med Today 1996;2:304-13.

81. Hu DD, Hoyer JR, Smith JW. Ca2+ suppresses cell adhesion to osteopontin by attenuating binding affinity for integrin $\alpha v \beta 3$. J Biol Chem 1995;270 9) $17-25$

82. Hruska KA, Rolnick F, Huskey M, Alvarez U, Cheresh D. Engagement of the osteoclast integrin $\alpha \mathrm{v} \beta 3$ by osteopontin stimulates phosphatidylinositol 3-hydroxyl kinase activity. Endocrinology 1995;136:2984-92.

83. Bayless KJ, Meininger GA, Scholtz JM, Davis GE. Osteopontin is a ligand for the $\alpha 4 \beta 1$ integrin. J Cell Sci 1998;111:1165-74.
84. Smith LL, Cheung HK, Ling LE, et al. Osteopontin N-terminal domain contains a cryptic adhesive sequence recognized by $\alpha 9 \beta 1$ integrin. J Biol Chem 1996;271:28485-91.

85. Denda S, Reichardt LF, Muller U. Identification of osteopontin as a novel ligand for the integrin $\alpha 8 \beta 1$ and potential roles for this integrin-ligand interaction in kidney morphogenesis. Mol Biol Cell 1998;9:1425-35.

86. Liaw L, Lindner V, Schwartz SM, Chambers AF, Giachelli CM. Osteopontin and $\beta 3$ integrin are coordinately expressed in regenerating endothelium in vivo and stimulate Arg-Gly-Asp-dependent endothelial migration in vitro. Circ Res 1995;77:665-72.

87. Senger DR, Perruzzi CA. Cell migration promoted by a potent GRGDScontaining thrombin-cleavage fragment of osteopontin. Biochim Biophys Acta 1996;1314:13-24.

88. Senger DR, Brown LF, Perruzzi CA, Papadopoulos-Sergiou A, Van de Water $\mathrm{L}$. Osteopontin at the tumor/host interface. Functional regulation by thrombin-cleavage and consequences for cell adhesion. Ann N Y Acad Sci 1995;760:83-100

89. Senger DR, Perruzzi CA, Papadopoulos-Sergiou A, Tenen DG. Purification of a human milk protein closely similar to tumor-secreted phosphoproteins and osteopontin. Biochim Biophys Acta 1989;996:43-8.

90. Bayless KJ, Davis GE. Identification of dual $\alpha 4 \beta 1$ integrin binding sites within a 38 amino acid domain in the N-terminal thrombin fragment of human osteopontin. I Biol Chem 2001;276:13483-9.

91. Agnihotri $R$, Crawford HC, Haro $H$, Matrisian LM, Havrda MC, Liaw L. Osteopontin, a novel substrate for matrix metalloproteinase-3 (stromelysin-1) and matrix metalloproteinase-7 (matrilysin). J Biol Chem 2001;276: $28261-7$.

92. Senger DR, Perruzzi CA, Papadopoulos-Sergiou A, Van de Water L. Adhesive properties of osteopontin: regulation by a naturally occurring thrombin-cleavage in close proximity to the GRGDS cell-binding domain. Mol Biol Cell 1994;5:565-74

93. Yokasaki Y, Sheppard D. Mapping of the cryptic integrin-binding site in osteopontin suggests a new mechanism by which thrombin can regulate inflammation and tissue repair. Trends Cardiovasc Med 2000;10:155-9.

94. Ponta $H$, Wainwright $D$, Herrlich P. The CD44 protein family. Int J Biochem Cell Biol 1998;30:299-305.

95. Herrera-Gayol A, Jothy S. Adhesion proteins in the biology of breast cancer: contribution of CD44. Exp Mol Pathol 1999:66:149-56.

96. Goodison S, Urquidi V, Tarin D. CD44 cell adhesion molecules. J Clin Pathol 1999;52:189-96.

97. Weber GF, Ashkar S, Glimcher MJ, Cantor H. Receptor-ligand interaction between CD44 and osteopontin (Eta-1). Science 1996;271:509-12.

98. Katagiri YU, Sleeman J, Fujii $H$, et al. CD44 variants but not CD44s cooperate $\beta 1$-containing integrins to permit cells to bind to osteopontin independently of arginine-glycine-aspartic acid thereby stimulating cell motility and chemotaxis. Cancer Res 1999;59:219-26.

99. Khan SA, Cook AC, Kappil M, et al. Enhanced cell surface CD44 variant $(v 6, v 9)$ expression by osteopontin in breast cancer epithelial cells facilitates tumor cell migration: novel post-transcriptional, post-translational regulation. Clin Exp Metastasis 2005;22:663-73.

100. Weber GF, Ashkar S, Cantor H. Interaction between CD44 and osteopontin as a potential basis for metastasis formation. Proc Assoc Am Physicians 1997;109:1 - 9 .

101. Senger DR, Wirth DF, Hynes RO. Transformed mammalian cells secrete specific proteins and phosphoproteins. Cell 1979;16:885-93.

102. Senger DR, Wirth DF, Hynes RO. Transformation-specific secreted phosphoproteins. Nature 1980;268:619-21.

103. Prince $\mathrm{CW}$. Secondary structure predictions for rat osteopontin. Connect Tissue Res 1989;21:15-20.

104. Smith JH, Denhardt DT. Molecular cloning of a tumor promoter-inducible mRNA found in JB6 mouse epidermal cells: induction is stable at high, but not at low, cell densities. J Cell Biochem 1987;34:13-22

105. Craig AM, Nemir M, Mukherjee BB, Chambers AF, Denhardt DT Identification of the major phosphoprotein secreted by many rodent cell lines as 2ar/osteopontin: enhanced expression in H-ras-transformed 3T3 cells. Biochem Biophys Res Commun 1988;157:166-73.

106. Chambers AF, Behrend EI, Wilson SM, Denhardt DT. Induction of expression of osteopontin (OPN; secreted phosphoprotein) in metastatic, ras-transformed NIH 3T3 cells. Anticancer Res 1992;12:43-7.

107. Chambers AF, Tuck AB. Ras-responsive genes and tumor metastasis. Crit Rev Oncog 1993;4:95-114.

108. Craig AM, Bowden GT, Chambers AF, et al. Secreted phosphoprotein mRNA is induced during multi-stage carcinogenesis in mouse skin and correlates with the metastatic potential of murine fibroblasts. Int ] Cancer 1990;46:133-7.

109. Uede T, Katagiri Y, lizuka J, Murakami M. Osteopontin, a coordinator of host defense system: a cytokine or an extracellular adhesive protein? Microbiol Immunol 1997:41:641-8.

110. Ramos KS. Redox regulation of c-Ha-ras and osteopontin signalling in vascular smoth muscle cells: implications in chemical atherogenesis. Annu Rev Pharmacol Toxicol 1999;39:243-65.

111. Mizejewski GJ. Role of integrins in cancer: survey of expression patterns Proc Soc Exp Biol Med 1999:222:124-38.

112. Varner JA, Cheresh DA. Integrins and cancer. Curr Opin Cell Biol 1996;8 $724-30$

113. Clezardin $P$. Recent insights into the role of integrins in cancer metastasis Cell Mol Life Sci 1998;54:541-8. 
114. Orr FW, Wang HH, Lafrenie RM, Scherbarth S, Nance DM. Interactions between cancer cells and the endothelium in metastasis. J Pathol 2000;190: $310-29$.

115. Seftor RE, Seftor EA, Hendrix MJ. Molecular role(s) for integrins in human melanoma invasion. Cancer Metastasis Rev 1999;18:359-75.

116. Wong NC, Mueller BM, Barbas $C F$, et al. $\alpha \mathrm{v}$ Integrins mediate adhesion and migration of breast carcinoma cell lines. Clin Exp Metastasis 1998;16:50-61.

117. Tuck AB, Elliott BE, Hota C, Tremblay E, Chambers AF. Osteopontininduced, integrin-dependent migration of human mammary epithelial cells involves activation of the hepatocyte growth factor receptor (Met). J Cell Biochem 2000;78:465 75.

118. Ellison JA, Velier JJ, Spera P, et al. Osteopontin and its integrin receptor av 33 are upregulated during formation of the glial scar after focal stroke. Stroke 1998;29:1698-706.

119. Carey I, Williams CL, Ways DK, Noti JD. Overexpression of protein kinase $\mathrm{C}-\alpha$ in MCF-7 breast cancer cells results in differential regulation and expression of $\alpha v \beta 3$ and $\alpha v \beta 5$. Int J Oncol 1999;15:127-36.

120. Noti JD. Adherence to osteopontin via $\alpha \mathrm{v} \beta 3$ suppresses phorbol estermediated apoptosis in MCF-7 breast cancer cells that overexpress protein kinase C- $\alpha$. lint J Oncol 2000;17:1237-43.

121. Zohar R, Suzuki N, Suzuki K, et al. Intracellular osteopontin is an integral component of the CD44-ERM complex involved in cell migration. J Cell Physiol 2000;184:118-30.

122. Fujisaki $T$, Tanaka $Y$, Fujii $K$, et al. CD44 Stimulation induces integrinmediated adhesion of colon cancer cell lines to endothelial cells by upregulation of integrins and c-Met and activation of integrins. Cancer Res 1999;59:4427-34

123. Agrawal D, Chen T, Irby $R$, et al. Osteopontin identified as lead marker of colon cancer progression, using pooled sample expression profiling. I Natl Cancer lnst 2002;94:513-21.

124. Senger DR, Perruzzi CA. Secreted phosphoprotein markers for neoplastic transformation of human epithelial and fibroblastic cells. Cancer Res 1985 ; 45:5818-23.

125. Rudland PS, Platt-Higgins A, El-Tanani M, et al. Prognostic significance of the metastasis-associated protein osteopontin in human breast cancer. Cancer Res 2002;62:3417-27.

126. Oates AJ, Barraclough R, Rudland PS. The identification of osteopontin as a metastasis-related gene product in a rodent mammary tumour model. Oncogene 1996;13:97-104.

127. Su L, Mukherjee AB, Mukherjee BB. Expression of antisense osteopontin mRNA inhibits tumor promoter-induced neoplastic transformation of mouse JB6 epidermal cells. Oncogene 1995;10:2163-9.

128. Behrend EI, Craig AM, Wilson SM, Denhardt DT, Chambers AF. Reduced malignancy of ras-transformed NIH 3T3 cells expressing antisense osteopontin RNA. Cancer Res 1994:54:832-7.

129. Sato $\mathrm{M}$, Morii $\mathrm{E}$, Komori $\mathrm{T}$, et al. Transcriptional regulation of osteopontin gene in vivo by PEBP2 $\alpha A / C B F A 1$ and ETS1 in the skeletal tissues. Oncogene 1998; 17:1517-25

130: Noda $M$, Vogel RL, Craig AM, et al. Identification of a DNA sequence responsible for binding of the 1,25-dihydroxyvitamin $D_{3}$ receptor and 1,25 . dihydroxyvitamin $D_{3}$ enhancement of mouse secreted phosphoprotein 1 (Spp-1 or osteopontin) gene expression. Proc Natl Acad Sci U S A 1990;87: 9995-9.

131. Bidder M, Shao JS, Charlton-Kachigian $N$, et al. Osteopontin transcription in aortic vascular smooth muscle cells is controlled by glucose-regulated upstream stimulatory factor and activator protein-1 activities. J Biol Chem 2002;277:44485-96.

132. El-Tanani M, Platt-Higgins A, Rudland PS, Campbell FC. Ets gene PEA3 cooperates with $B$-catenin-Lef- 1 and $c$-Jun in regulation of osteopontin transcription. J Biol Chem 2004;279:20794-806.

133. Webb CP, Taylor GA, Jeffers M, et al. Evidence for a role of Met-HGF/SF during Ras-mediated tumorigenesis/metastasis. Oncogene 1998;17:2019-25.

134. Trusolino $L$, Cavassa $S$, Angelini $P$, et al. HGF/scatter factor selectively promotes cell invasion by increasing integrin avidity. FASEB J 2000;14 $1629-40$.

135. Andreasen PA, Kjoller L, Christensen L, Duffy MJ. The urokinase-type plasminogen activator system in cancer metastasis: a review. Int J Cancer 1997;72:1-22.

136. Chambers AF, Matrisian LM. Changing views of the role of matrix metalloproteinases in metastasis. J Nat] Cancer Inst 1997;89:1260-70.

137. DeClerck YA. Interactions between tumour cells and stromal cells and proteolytic modification of the extracellular matrix by metalloproteinases in cancer. Eur J Cancer 2000;36:1258-68.

138. Nguyen DH, Catling AD, Webb DJ, et al. Myosin light chain kinase functions downstream of RAS/ERK to promote migration of urokinase-type plasminogen activator-stimulated cells in an integrin-selective manner. J Cell Biol 1999;146:149-64.

139. Tuck $A B$, Arsenault DM, $O^{\prime}$ Malley FP, et al. Osteopontin ind uces increased invasiveness and plasminogen activator expression of human mammary epithelial cells. Oncogene 1999;18:4237-46.

140. Yebra M, Parry GC, Stromblad S, et al. Requirement of receptor-bound urokinase-type plasminogen activator for integrin $\alpha v 335$-directed cell migration. J Biol Chem 1996;271:29.393-9.

141. Carriero MV, Del Vecchio $S$, Capozzoli $M$, et al. Urokinase receptor interacts with $\alpha v \beta 5$ vitronectin receptor, promoting urokinase-dependent cell migration in breast cancer. Cancer Res 1999;59:5307-14

142. Aguirre Ghiso JA, Kovalski K, Ossowski L. Tumor dormancy induced by downregulation of urokinase receptor in human carcinoma involves integrin and MAPK signalling. J Cell Biol 1999;147:89-104

143. Teti A, Farina AR, Villanova $I$, et al. Activation of MMP-2 by human GCT23 giant cell tumour cells induced by osteopontin, bone sialoprotein and GRGDSP peptides is RGD and cell shape change dependent. Int J Cancer 1998;77:82-93.

144. Bendeck MP, lrvin $C$, Reidy $M$, et al Smooth muscle cell matrix metalloproteinase production is stimulated via $\alpha \mathrm{vB3}$ integrin. Arterioscler Thromb Vasc Biol 2000;20:1467 -72

145. Costa C, Soares R, Schmitt F. Angiogenesis: now and then. Acta Pathol Microbiol Immunol Scand 2004;112:402-12

146. Soares R, Reis-Filho J, Gartner F, Schmitt F. VEGF, TGF $\alpha$ and estrogen receptors: possible crosstalks and interactions. Am J Pathol 2002;160:381 -2

147. Soares R, Guo S, Russo J, Schmitt F. Role of the estrogen antagonist ICI 182,780 in vessel assembly and apoptosis of endothelial cells. Ultrastruct Pathol 2003;27:33-9.

148. Soares R, Balogh G, Guo S, Gartner F, Russo J, Schmitt F. Evidence for the notch signaling pathway on the role of estrogen in angiogenesis. Mol Endocrinol 2004:18:2333-43.

149. Brooks PC, Clark RA, Cheresh DA. Requirement of vascular integrin av 33 for angiogenesis. Science 1994;264:569-71

150. Brooks PC, Montgomery AM, Rosenfeld $M$, et al. Integrin $\alpha v \beta 3$ antagonists promote tumor regression by inducing apoptosis of angiogenic blood vessels. Cell 1994:79:1157-64.

151. Scatena M, Almeida M, Chaisson ML, Fausto N, Nicosia RF, Giachelli CM. NF- $\mathrm{B}$ mediates $\alpha v B 3$ integrin-induced endothelial cell survival. J Cell Biol 1998; $141: 1083-93$

152. Malyankar UM, Scatena M Suchland KL, Yun TI Clark EA, Giachelli CM Osteoprotegerin is an $\alpha \mathrm{v} \beta 3$-induced, NF- $\kappa$ B-dependent survival factor for endothelial cells. J Biol Chem 2000;275:20959-62.

153. Senger DR, Ledbetter SR, Claffey KP, Papadopoulos-Sergiou A, Peruzzi CA Detmar M. Stimulation of endothelial cell migration by vascular permeability factor/vascular endothelial growth factor through cooperative mechanisms involving the $\alpha \mathrm{V} \beta 3$ integrin, osteopontin, and thrombin. Am J Pathol 1996;149:293-305.

154. Takano S, Tsuboi K, Tomono Y, Mitsui Y, Nose T. Tissue factor, osteopontin, av33 integrin expression in microvasculature of gliomas associated with vascular endothelial growth factor expression. Br J Cancer 2000;82:1967-73.

155. Shijubo N, Uede T, Kon $S$, et al. Vascular endothelial growth factor and osteopontin in stage I lung adenocarcinoma. Am J Respir Crit Care Med $1999 ; 160: 1269-73$

156. Denhardt DT, Chambers AF. Overcoming obstacles to metastasis-defenses against host defenses: osteopontin (OPN) as a shield against attack by cytotoxic host cells. J Cell Biochem 1994;56:48-51

157. Rollo EE, Denhardt DT. Differential effects of osteopontin on the cytotoxic activity of macrophages from young and old mice. Immunology 1996;88: $642-7$

158. Feng B, Rollo EE, Denhardt DT. Osteopontin (OPN) may facilitate metastasis by protecting cells from macrophage NO-mediated cytotoxicity: evidence from cell lines down-regulated for OPN expression by a targeted ribozyme. Clin Exp Metastasis 1995;13:453-62.

159. Hwang SM, Lopez CA, Heck DE, et al. Osteopontin inhibits induction of nitric oxide synthase gene expression by inflammatory mediators in mouse kidney epithelial cells. J Biol Chem 1994;269:711-5.

160. Rollo EE, Laskin DL, Denhardt DT. Osteopontin inhibits nitric oxide production and cytotoxycity by activated RA W264.7 macrophages. J I.eukoc Biol 1996;60:397-404

161. Scott JA, Weir ML, Wilson SM, Xuan JW, Chambers AF, McCormack DG. Osteopontin inhibits inducible nitric oxide synthase activity in rat vascular tissue. Am J Physiol 1998:275: $\mathrm{H} 2258-65$

162. Thomsen LL, Miles DW. Role of nitric oxide in tumour progression: lessons from human tumours. Cancer Metastasis Rev 1998;17:107-18.

163. Brennan PA. The actions and interactions of nitric oxide in solid tumours. Eur J Surg Oncol 2000;26:434-7.

164. Kolb JP. Mechanisms involved in the pro- and anti-apoptotic role of NO in human leukemia. Leukemia 2000;14:1685-94

165. Chambers AF, Wilson SM, Kerkvliet N, O'Malley FP, Harris JF, Casson AG. Osteopontin expression in lung cancer. Lung Cancer 1996;15:311-23.

166. Tuck $A B$, O'Malley FP, Singhal $\mathrm{H}$, et al. Osteopontin expression in a group of lymph node negative breast cancer patients. Int J Cancer 1998:79:502-8.

167. Casson AG, Wilson SM, McCart JA, et al. ras mutation and expression of the ras-regulated genes osteopontin and cathepsin L in human esophageal cancer. Int J Cancer 1997;72:739-45.

168. Ue $\mathrm{T}$, Yokozaki $\mathrm{H}$, Kitadai $\mathrm{Y}$, et al. Co-expression of osteopontin and CD44v9 in gastric cancer. Int J Cancer 1998;79:127-32.

169. Thalman GN, Sikes RA, Devoll RE, et al. Osteopontin: possible role in prostate cancer progression. Clin Cancer Res 1999;5:2271-7.

170. Saitoh Y, Kuratsu JI, Takeshima H, Yamamoto S, Ushio Y. Expression of osteopontin in human glioma. Its correlation with the malignancy. Lab lnvest 1995;72:53-5.

171. Oates AJ, Barraclough R, Rudland PS. The role of osteopontin in tumorigenesis and metastasis. Invasion Metastasis 1997;17:1-15.

172. Hirota S, Ito A, Nagoshi J, et al. Expression of bone matrix protein messenger ribonucleic acids in human breast cancers. Possible involvement of osteopontin in development of calcifying foci. Lab Invest 1995;72:64-9.

173. Bellahcene A, Castronovo V. Expression of bone matrix proteins in human breast cancer: potential roles in microcalcification formation and in the genesis of bone metastases. Bull Cancer 1997;84:17-24 
174. Maki M, Hirota S, Kaneko Y, Morohoshi T. Expression of osteopontin messenger RNA by macrophages in ovarian serous papillary cystadenocarcinoma: a possible association with calcification of psammoma bodies. Pathol Int 2000;50:531-5.

175. Hirota S, Nakajima Y, Yoshimine T, et al. Expression of bone-related protein messenger RNA in human meningiomas: possible involvement of osteopontin in development of psammoma bodies. J Neuropathol Exp Neurol 1995;54:698-703

176. Tunio GM, Hirota S, Nomura S, Kitamura Y. Possible relation of osteopontin to development of psammoma bodies in human papillary thyroid cancer. Arch Pathol Lab Med 1998;122:1087-90.

177. Tuck $A B$, O'Malley FP, Singhal $\mathrm{H}$, et al. Osteopontin and $\mathrm{p} 53$ expression are associated with tumor progression in a case of synchronous, bilateral, invasive mammary carcinomas. Arch Pathol Lab Med 1997;121:578-84.

178. Tozawa K, Yamada Y, Kawai N, Okamura T, Ueda K, Kohri K. Osteopontin expression in prostate cancer and benign prostatic hyperplasia. Urol Int $1999 ; 62: 155-8$.

179. Tiniakos DG, Yu H, Liapis $\mathrm{H}$. Osteopontin expression in ovarian carcinomas and tumors of low malignant potential (LMP). Hum Pathol 1998;29:1250-4.

180. Liapis H, Adler LM, Wick MR, Rader JS. Expression of av $\beta 33$ integrin is less frequent in ovarian epithelial tumors of low malignant potential in contrast to ovarian carcinomas. Hum Pathol 1997:28:443-9.

181. Brown LF, Papadopoulos-Sergiou A, Berse B, et al. Osteopontin expression and distribution in human carcinomas. Am J Pathol 1994;145:610-23.

182. Bautista DS, Saad Z, Chambers AF, et al. Quantification of osteopontin in human plasma with an ELISA: basal levels in pre- and postmenopausal women. Clin Biochem 1996;29:231-9.

183. Singhal H, Bautista DS, Tonkin KS, et al. Elevated plasma osteopontin in metastatic breast cancer associated with increased tumor burden and decreased survival. Clin Cancer Res 1997:3:605-11.

184. Vanacker JM, Pattersson K, Gustafsson JA, Laudet V. Transcriptional targets shared by estrogen receptor-related receptors (ERRs) and estrogen receptor (ER) $\alpha$, but not by (ER) $\beta$. EMBO J 1999;18:4270-9.

185. Etzioni R, Urban N, Ramsey $S$, et al. The case for early detection. Nat Rev Cancer 2003:3:243-52.

186. Hayes DF. Serum (circulating) tumour markers for breast cancer. Recent Results Cancer Res 1996;140:101-13.

187. O'Brien N, Maguire TM, O'Donovan N, et al. Mammaglobin: a promising marker for breast cancer. Clin Chem 2002;48:1362-4

188. Maass N, Nagasaki K, Ziebart M, Mundhenke C, Jonat W. Expression and regulation of tumor suppressor gene maspin in breast cancer. Clin Breast Cancer 2002;3:281-7.

189. Corradini $P$, Voena $C$, Astolfi $M$, et al. Maspin and mammaglobin genes are specific markers for RT-PCR detection of minimal residual disease in patients with breast cancer. Ann Oncol 2001;12:1693-8.
190. Kinoshita J, Kitamura K, Kabashima A, Saeki H, Tanaka S, Sugimachi K. Clinical significance of vascular endothelial growth factor-C (VEGF-C) in breast cancer. Breast Cancer Res Treat 2001;66:159-64

191. Sanchez R, Nguyen D, Rocha W, White JH, Mader S. Diversity in the mechanisms of gene regulation by estrogen receptors. Bioassays 2002;24: $244-54$.

192. Ariazi EA, Clark GM, Mertz JE. Estrogen-related receptor alfa and estrogen-related receptor gama associate with unfavorable and favorable biomarkers, respectively, in human breast cancer. Cancer Res 2002;62: $6510-8$.

193. MacGrogan G, Jollet I, Huet S, et al. Comparison of quantitative and semiquantitative methods of assessing MIB-1 with the S-phase fraction in breast carcinoma. Mod Pathol 1997;10:769-76.

194. Mitas M, Mikhitarian K, Walters $C$, et al. Quantitative real-time RT-PCR detection of breast cancer micrometastasis using a multigene marker panel. Int J Cancer 2001;93:162-71.

195. Sjogren S, Inganas M, Lindgren A, Holmberg L, Bergh J. Prognostic and predictive value of c-erbB-2 overexpression in primary breast cancer, alone and in combination with other prognostic markers. J Clin Oncol 1998;16: $462-9$.

196. Paredes J, Milanezi F, Viegas L, Amendoeira I, Schmitt F. P-cadherin expression is associated with high-grade ductal carcinoma in situ of the breast. Virchows Arch 2002;440:16-21.

197. Paredes J, Stove C, Stove V, et al. P-Cadherin is up-regulated by the antiestrogen ICI 182,780 and promotes invasion of human breast cancer cells. Cancer Res 2004;64:8309-17.

198. Matos I, Dufloth R, Alvarenga M, Zeferino LC, Schmitt F. p63, cytokeratin 5 , and P-cadherin: three molecular markers to distinguish basal phenotype in breast carcinomas. Virchows Arch 2005;447:688-94.

199. Brakora KA, Lee $H$, Yusuf $R$, et al. Utility of osteopontin as a biomarker in recurrent epithelial ovarian cancer. Gynecol Oncol 2004;93:361 -5.

200. Fisher $L W$, Jain $A$, Tayback $M$, Fedarko NS. Small integrin binding ligand Nlinked glycoprotein gene family expression in different cancers. Clin Cancer Res 2004;10:8501-11.

201. Ganss B, Kim RH, Sodek J. Bone sialoprotein. Crit Rev Oral Biol Med 1999; 10:79-98.

202. Liaw L, Skinner MP, Raines EW, et al. The adhesive and migratory effects of osteopontin mediated via distinct cell surface integrins. Role of $\alpha v \beta 3$ in sinooth muscle cell migration to osteopontin in vitro. J Clin Invest 1995;95: $713-24$.

203. Barry ST, Ludbrook SB, Murrison E, Horgan CM. A regulated interaction between $\alpha 5 \beta 1$ integrin and osteopontin. Biochem Biophys Res Commun 2000;267:764-9.

204. Barry ST, Ludbrook SB, Murrison E, Horgan CM. Analysis of the $\alpha 4 \beta 1$ integrin-osteopontin interaction. Exp Cell Res 2000;258:342-51. 